\title{
La política pública de inclusión: utopía de la gestión educativa en Colombia*
}

\author{
Lina María Castro Castaño*
}

Recibido: 19 de agosto de 2019 • Aprobado: 24 de octubre de 2019

\section{Resumen}

El presente artículo hace referencia a la configuración de la política de inclusión. Este planteamiento requiere un análisis desde las representaciones que se tiene respecto de la gestión educativa en la implementación de la política; de allí que su propósito sea comprender la configuración de la inclusión como política y las representaciones de la gestión educativa para su implementación. En este sentido, la reflexión se desarrolla desde una investigación con alcance descriptivo, que busca especificar la configuración de la política desde la filosofía. Durante el proceso de investigación el diseño transeccional descriptivo permitió presentar el origen de la inclusión de forma transversal a la gestión educativa, y el método de datos secundarios implicó la revisión de la evolución de la política pública de inclusión en Colombia, con el fin de favorecer la reflexión de manera contextualizada. De esta manera, se reafirma la utopía como la meta que se encuentra en el horizonte y que, cada vez que el sistema se acerca, esta se aleja más. Se parte del recorrido histórico de la política pública educativa; luego, se continúa con los elementos de las representaciones $\mathrm{y}$, por último, se plantea la utopía del sistema educativo, representada en la política de inclusión.

Palabras clave: gestión educativa, política de inclusión educativa, representaciones sociales.

* Este artículo de investigación es producto de la reflexión en el marco del proyecto Comprensión de la Política Pública de Inclusión Educativa, financiado con recursos propios, para obtener el título de Doctorado en Educación, de la Universidad de Baja California, México. Citar como: Castro, L. (2020). La política pública de inclusión: utopía de la gestión educativa en Colombia. Análisis, 52(96), 59-80. Dol: https://doi.org/10.15332/21459169/5295

** Maestra en Educación de la Diversidad de la Universidad de Manizales. Directiva docente de la Institución Educativa CASD (Armenia, Quindío). Docente catedrática de la Universidad del Quindío. Correo electrónico: linacastro@casdquindio. edu.co Icastro@uniquindio.edu.co. orcid: https://orcid.org/0000-0002-4936-3457 


\title{
Public policy of inclusion: utopia of educational management in Colombia
}

\author{
Lina María Castro Castaño
}

\section{Abstract}

This article refers to the configuration of the inclusion policy. This approach requires an analysis from the representations we have regarding educational management in the implementation of the policy; hence its purpose is to understand the configuration of inclusion as a policy and the representations of educational management for its implementation. In this sense, the reflection is developed from a research with a descriptive scope, which seeks to specify the configuration of the policy from philosophy. During the research process the descriptive cross-sectional design allowed presenting the origin of the inclusion in a cross-sectional way to the educational management, and the secondary data method implied the revision of the evolution of the public policy of inclusion in Colombia, in order to favor the reflection in a contextualized way. Consequently, the utopia is reaffirmed as the goal that is on the horizon and that, every time the system approaches, moves further away. It starts from the historical path of educational public policy; then, continues with the elements of the representations and, finally, the utopia of the educational system, represented in the inclusion policy, is proposed.

Keywords: educational management, inclusive education policy, social representations. 


\section{La politique publique d'inclusion : \\ I'utopie de la gestion éducative en Colombie}

Lina María Castro Castaño

\section{Résumé}

Cet article vise à comprendre la configuration de la politique d'inclusion, ce qui appelle à une analyse les représentations qui existent sur le sujet. En ce sens, le but principal consiste à saisir l'inclusion comme objet d'une politique publique, ainsi que les représentations que l'on se forme à propos de la gestion éducative censée les appliquer. Afin d'accomplir un tel dessein, cette recherche descriptive tente de spécifier, d'abord, la configuration philosophique de la politique d'inclusion, puis de remettre le contexte général des politiques publiques d'inclusion en Colombie. Ainsi, on essaye d'affirmer l'utopie comme ce qui se trouve à l'horizon, toujours au-delà des efforts fait par le système éducatif.

Mots clés: gestion éducative, politique d'inclusion éducative, représentations sociales. 


\section{Introducción}

El presente artículo pretende reflexionar sobre la política de inclusión educativa, desde el recorrido de su comprensión en las diferentes épocas y las afectaciones en la representación de la discapacidad, asumido en un principio el sujeto como defectuoso, para llegar a la modernidad y posmodernidad como un sujeto de derechos visibilizado desde las representaciones sociales, partícipe de la política inclusiva. Para comprender la política pública se hace un debate conceptual, poniendo en evidencia la limitación de la inclusión a la discapacidad, planteamiento que genera situaciones de exclusión. Para finalizar emerge la utopía que ubica la política pública de inclusión educativa en Colombia como la meta en cada Plan de desarrollo del gobierno de turno, pero que al final del periodo gubernamental no alcanza a llegar al sujeto estudiante, y peor aún vive la ambigüedad entre las diferentes normas o se anulan entre sí, dejando de lado la atención de los niños, niñas y jóvenes, con planteamientos reduccionistas del concepto de calidad y de cobertura como la permanencia de un número significativo de estudiantes en el aula, sin discriminar la atención, la educación.

La política pública de inclusión se convierte en el paradigma que trasciende todos los sistemas, con ideologías de democracia, corresponsabilidad, libertad, autonomía, equidad y diversidad; sin embargo, en su implementación resulta excluyente y reducida a indicadores estadísticos, que no reflejan la realidad del país.

\section{Generalidades teóricas}

La investigación en torno a la inclusión educativa ha cobrado gran importancia en los últimos años. En este proceso se hace necesaria la revisión de investigaciones en torno a la implementación de la política pública de inclusión desde la gestión educativa. Una recurrencia que encuentran los investigadores que indagan sobre la gestión educativa es la exclusión que hace la misma inclusión al referirse de manera puntual a las necesidades educativas especiales, casi como único campo de acción; por lo tanto, para el análisis se tuvieron en cuenta investigaciones realizadas en diferentes países, cuyos investigadores comparten la misma preocupación frente a la implementación de la política pública de inclusión. Es así como el Centro de Investigación y Documentación Educativa de España presenta la investigación en torno a "las paradojas y dilemas importantes a los que se enfrentan los principales actores en este proceso $\mathrm{y}$, en todo caso, pone en evidencia la existencia de barreras de distinto tipo que impiden el disfrute del derecho a una educación inclusiva" (Echeita et al., 2009, p. 2). Otras investigaciones van más allá del planteamiento de la inclusión en el sistema educativo, ubicándola en la educación intercultural. De esta forma, la inclusión educativa se contempla de forma global, se dirige a todos los estudiantes y no solo a los diagnosticados con necesidades educativas especiales (Aguado, 2004). Además, en la justicia social "se asume que el objetivo de la 
educación inclusiva es eliminar la exclusión social que resulta de ciertas actitudes y respuestas ante la diversidad racial, social, étnica, religiosa, de género y de habilidades" (Vitello \& Mithaug, 1998, p. 2, citado por Ainscow, 2004); por su parte, González (2008), si bien expresa la inclusión desde el sistema educativo, la ubica desde la organización:

\begin{abstract}
Cuando hablamos de escuela inclusiva la propia expresión nos remite a - escuela-, acentuando así la importancia de las condiciones y capacidades de la organización escolar que hagan posible la inclusión. Ésta no se dirime únicamente en el aula, ni es el resultado de actuaciones de personas individuales que hacen cosas admirables pero en aislamiento; es el centro en su conjunto el que ha de articular respuestas coherentes y globales a los retos que representa la diversidad. (p. 4)
\end{abstract}

Moliner (2008) opina que es fundamental el liderazgo político y administrativo que tratará de hacer oficial la inclusión. Es importante que este liderazgo se ejerza, puesto que se va a traducir en políticas de financiación y distribución de fondos. Otros investigadores hacen alusión a la cuestión de la inclusión desde la capacitación docente para atender a los niños, niñas y jóvenes en su diversidad: "la construcción de políticas compensatorias en educación ha presionado fuertemente la formación de profesionales que sean capaces de reconocer y valorar la diversidad, de modo de (sic) promover comunidades educativas inclusivas" (Infante, 2010, p. 7). Las dificultades de los docentes, los vacíos en el campo pedagógico, las demandas de mejores condiciones laborales, etc., afectan el servicio educativo para niños, niñas y jóvenes en su totalidad.

\title{
Metodología de la revisión
}

La localización de investigaciones relevantes en el ámbito de la política pública de inclusión ha implicado recurrir a fuentes documentales diversas. Las fuentes consultadas provienen de bases de datos tales como Redalyc, CIDE, Scielo; buscadores especializados como Google Académico, y legislación vigente especialmente de Colombia, consultada en la página de la Presidencia de la República. La búsqueda ha sido multidisciplinar, en coherencia con el carácter del marco conceptual, y se genera tanto en el campo pedagógico como en el de la psicología y la filosofía.

\section{El método}

Respecto al método utilizado, se trató de datos secundarios, por medio de aportes de otros investigadores, revisión de documentos, leyes y decretos emanados del gobierno Nacional de Colombia. Asimismo, se incluyen tratados internacionales que afectan directamente el tema de estudio, como constitutivo en el campo de lo universal, libros en físico y digitales; además, se incluye el enlace de consulta 
y la fecha de recuperación de la referencia bibliográfica. Se enfocó la búsqueda en la política pública, la inclusión, las representaciones sociales y la gestión educativa, recolectados y organizados en ficheros bibliográficos.

\section{Criterios de exclusión e inclusión}

Se consideraron como criterios de exclusión los documentos relacionados con el índice de desarrollo inclusivo, ya que corresponden a un requisito económico. En el caso de Colombia la última medición se dio durante el presente año y la elaboró el Foro Económico Mundial (FEM), quien considera, para el caso del pilar de inclusión, tener en cuenta la mediana del ingreso familiar, tasa de pobreza, ingreso y riqueza.

En los criterios de inclusión, se dio importancia a la legislación internacional sobre la política de inclusión educativa, a los documentos que desde la filosofía permiten constatar el proceso de inclusión en cada época y a las investigaciones que permiten conceptualizar la inclusión más allá de la discapacidad.

\section{Marco teórico}

Para el desarrollo del marco teórico se plantean tres momentos: el primero, desde el debate filosófico que permite comprender la configuración de la política como pública y sus contradicciones en el proceso histórico de los modelos explicativos de la discapacidad; el segundo, en el debate conceptual, que muestra el estado del arte de la política pública de inclusión; y en el tercero se presenta la discusión en torno a la inclusión como la utopía de la gestión educativa en Colombia.

\section{Filosofía de la política de inclusión}

El recorrido histórico de la política inicia con planteamientos desde la filosofía. En la antigua Grecia, cuando los hombres comenzaron a pensar en sus derechos y consideraron que tenían la obligación de participar en las decisiones de la sociedad, llamaron polis a sus ciudades, polites a los ciudadanos y politiké a la actividad pública de los polites. Aristóteles es quién da importancia a la política resaltando al hombre como un "animal político", situación que ubica al hombre como ser perteneciente a la naturaleza que se diferencia de los animales por ser el poseedor de pensamiento que se comunica con la envoltura de la palabra en una configuración de Estado, de bienes y de recursos, e incluso de formación que da origen al conocimiento y al avance de la misma sociedad. Al respecto Emmerich y Alarcón (2007) plantean que la filosofía política se interesa por el fundamento y la razón de ser del cuerpo político; en la República de Platón, se propone un modelo utópico de una polis ideal aplicable en todo tiempo y lugar. 
Sin embargo, y en contradicción con los planteamientos del "ser político" que forma parte de la sociedad, en paralelo se gesta el modelo de prescindencia, en el que la mirada del Estado es guiada por los principios religiosos, y el individuo en condición de discapacidad es considerado un castigo. Con la premisa "en cuánto a la exposición y crianza de los hijos, debe ordenarse que no se cría a ninguno defectuoso" (Azcárate, 1873, p. 60), Aristóteles deja entrever la consideración de que, al nacer en condición de discapacidad, se asume una condición que no permite hacer aportes a la sociedad, se convierte en una carga, se le asigna el rol de objeto para la diversión, es ridiculizado y los sacerdotes en representación de la iglesia son los llamados a "diagnosticar". Se consolidan así dos submodelos: el eugenésico y el marginal. "Desde el submodelo eugenésico, se considera que la persona con discapacidad, es un ser cuya vida no merece la pena ser vivida. Como consecuencia [...] los niños y niñas afectados son sometidos a infanticidio" (Palacio, 2008, p. 38). El submodelo marginal se manifiesta desde la exclusión: "[...] gran parte de los niños y niñas con discapacidad mueren como consecuencia de omisiones -ya sea por falta de interés y recursos, o por invocarse la fe como único medio de salvación -" (p. 54).

Posteriormente, la política vivió un avance en su configuración con los planteamientos del concepto de Estado. Es en Europa, durante los siglos XIV, xv y xvi, que se da el paso de las manifestaciones artísticas de la Edad Media a los inicios de la Edad Moderna, con un movimiento cultural que da vida a un nuevo nacimiento de las artes, pero que en especial afecta el pensamiento de los pueblos. En contraposición, el cristianismo, a la sombra de la inquisición, hace el tránsito a la comprensión de la diferencia como la posesión del demonio; es decir, la iglesia se enfoca en el perdón de los pecados y respalda el respeto a la vida, con el disfraz de los asilos, permitiendo que los niños y niñas en condición de discapacidad, cuando logran sobrevivir al abandono del Estado, accedan a servirle a la misma iglesia.

Aquí conviene detenerse un momento para puntualizar el tránsito de la política pública hacia la inclusión, y es que en la filosofía nuevamente se gesta la naturaleza de la diversidad, Hegel (citado por Rendón, 2012) señala lo siguiente:

La integración del individuo en el proceso social de producción y consumo, y su consiguiente derecho a participar del patrimonio general o riqueza así generado, opera en Hegel, por un lado, como refuerzo al reconocimiento jurídico que, en cuanto propietario, disfruta el individuo en el ámbito del derecho abstracto, donde la propiedad es la "primera existencia" de la "libertad". (p. 59)

Paralelamente en Inglaterra se da inicio a la revolución económica que daría paso a la primera Revolución Industrial de la que nos atañe la configuración política, en la que las transformaciones sociales dan origen al capitalismo y al proletariado. Desde la política, la burguesía tiene el poder y se impone sobre los aristócratas; posteriormente, durante el siglo xix se extiende a Estados Unidos y Japón, poniendo la ciencia al servicio de los inventos. Es justamente en los albores de 
la Revolución Industrial cuando se vislumbra la transformación del modelo de prescindencia: la llegada del conocimiento en su relación con la ciencia permite visibilizar, en primera instancia, la discapacidad como enfermedad mental.

Al mismo tiempo, la segunda Revolución Industrial no solo afecta el sistema económico, sino que determina cambios significativos en la organización política. Allí surge el término clases, con el que la burguesía se enfrenta al proletariado en defensa de su liberalismo financiero, se consolidan los movimientos obreros que inicialmente son de índole sindicalista y desembocan políticamente como socialismo y anarquía. Por el contrario, Alarcón (2007) afirma lo siguiente:

\begin{abstract}
Posteriormente hasta el movimiento del realismo político del siglo XX, [...] destacan pensadores como Carl Schmitt (1883-1988) o Hans Morgenthau (1904-1980), el cual postula el paso sustantivo hacia una construcción del poder basado en la cesión irrestricta de los intereses jurídicos a manos de un soberano legal para así poder realizar sus tareas de protección y seguridad. (p. 269)
\end{abstract}

Aunque la Segunda Guerra Mundial marcó cambios significativos en la comprensión de la discapacidad, el alto número de víctimas con consecuencias de mutilación reafirma el criterio de enfermedad: "La II Guerra Mundial también trae consigo otro tipo de aportaciones, concretamente, el nacimiento del movimiento rehabilitador y de la psicología de la rehabilitación y su expansión a otros campos" (Aguado, 1995, p. 182). Si bien se propone un cambio en el concepto de discapacidad, continúa la mirada del diferente que en este caso no se somete a la eugenesia, pero que será aislado, escondido, con la excusa de la rehabilitación y posterior integración social.

Según se ha citado son los acontecimientos de la Modernidad, los que traen la ciencia a lo que en un futuro se llamaría inclusión y que por ahora se presenta como una integración, el modelo de rehabilitación permite la mirada de la discapacidad como una condición de origen médico. De este modo, surgen las instituciones especializadas en la atención, y se da el tránsito de individuo a sujeto que necesita ser normalizado, la llegada de lo público a la política. Las dinámicas sociales y académicas hacen que los sujetos comiencen a pensar en la contribución de los otros para alcanzar sus propias metas. La academia hace el recorrido acelerado por las ciencias y, en la presentación de la ciencia política como lo plantea Lazzarato (2006), el acontecimiento muestra lo que una época tiene de intolerable, pero también hace emerger nuevas posibilidades de vida.

A pesar de que la política pública se enmarca en intereses de todo orden (especialmente el económico y el social, que convergen en el educativo), el desarrollo económico pone de antemano una relación directa con el sistema educativo, ya que las políticas de Estado buscan dar cumplimiento a objetivos generales que trascienden su propio territorio. En este sentido, Navarro (2006) plantea lo siguiente: 
Para entender por qué el cambio es difícil hay que comprender a los actores principales, sus preferencias y horizontes temporales, cómo se alinean sus intereses y, por ende, las posibilidades de conflicto o cooperación, así como los entornos en que se formula la política. Asimismo, exige comprender los elementos distintivos del proceso de formulación de políticas (PFP) en el sector educativo, y cómo ese PFP sectorial interactúa con el PFP general en los países. (p. 5)

Por otra parte, las políticas de estandarización, asumidas desde la globalización, esconden la representación materializada de un dispositivo de poder y de control, que enmascara el dominio sobre los sujetos que configuran la sociedad. Kjellen (citado por Esposito, 2004), comprende al Estado como forma viviente, un conjunto integrado de hombres que se comportan como un único individuo espiritual y corpóreo a la vez. Es decir, la configuración de Estado como único individuo gesta las relaciones de poder generadas y producidas en y desde los gobiernos, la población aparece como elemento necesario para controlar y dirigir a un grupo de sujetos por medio de diversos mecanismos de regularización.

Ahora bien, el modelo de rehabilitación contribuye en la configuración de Estado en el siglo $\mathrm{xx}$, como el encargado de regular no solo la discapacidad desde lo funcional y sensorial, sino también para enmascarar la atención a la discapacidad social, que en realidad queda fuera de la política. El Estado presenta el asistencialismo a través de instituciones especializadas para sordos, ciegos, víctimas de la guerra; justifica el gasto público en dicha atención, pero deja de lado el aumento de la injusticia social que afecta directamente el desarrollo social y limita el acceso a la educación.

En efecto, el sujeto en sus condiciones y capacidades específicas se reconoce en la medida en que forma parte del todo, de la universalidad, mediado por la autorregulación de su propio desarrollo cognitivo y emocional. Es el pensamiento de Hegel - quien aporta nuevos elementos a la configuración de Estado, la libertad y la ética - donde el hombre libre es real, ya que existe la organización en la familia, en la sociedad, y la ética existente en estas dos instituciones; solo se revela como pensamiento en el Estado, "por otro lado, como ampliación de la esfera de dicha libertad, al elevar las potencialidades y disposiciones éticoprácticas del individuo a condiciones sustanciales de la organización social de las clases" (Rendón, 2012, p. 59).

Es así como surge a mediados del siglo xx el modelo social, que considera la diferencia como parte de la dignidad humana. De esta manera, el sujeto desde su diversidad hace parte activa del colectivo y hace el llamado a la ética desde la escuela; tuvo su origen en los planteamientos de los derechos, desde el tratado internacional de los derechos humanos que establece las obligaciones que tienen los gobiernos de tomar medidas en determinadas situaciones, o de abstenerse de actuar de determinada forma en otras, a fin de promover y proteger los derechos humanos y las libertades fundamentales de los individuos o grupos; es decir que el modelo social emerge como la posibilidad en el marco de los derechos, para 
que el sujeto en condición de discapacidad agencie su propia vida, identificando las barreras sociales, económicas, culturales y educativas que el Estado permite y que han prevalecido desde la misma configuración de Estado.

\section{Configuración de la política pública de inclusión}

Sobre la base de las consideraciones anteriores, se formulan cambios que marcan históricamente las políticas de Estado. En efecto, la modernidad aporta planteamientos desde el ejercicio de los Derechos Humanos, que se consolidan en las políticas públicas de inclusión, que permiten contextualizar el horizonte de orden nacional y local. A finales de la década de 1980, se da la movilización desde los Derechos Humanos, y es en la convención de los derechos del niño de la Organización de las Naciones Unidas (onU, 1989) que los pueblos reafirman su fe en los derechos del hombre, en la dignidad y en el valor de la persona humana, en el progreso social y la elevación del nivel de vida dentro de un concepto de libertad. Posteriormente, en 1990 se llevó a cabo la Declaración Mundial de Educación para Todos: Satisfacción de las necesidades básicas de aprendizaje (Unesco, 1990), una conferencia que reunió en Jomtien, Tailandia, a 1.500 participantes, representantes de 155 Estados.

La Conferencia de Jomtien representó sin duda alguna un hito importante en el diálogo internacional sobre el lugar que ocupa la educación en la política de desarrollo humano; el consenso en ella alcanzado ha dado renovado impulso a la campaña mundial dirigida a proporcionar una enseñanza primaria universal y a erradicar el analfabetismo de los adultos. Además, ha suscitado esfuerzos con vistas a mejorar la calidad de la educación básica y a dar con los medios más eficaces y baratos para satisfacer las necesidades básicas de aprendizaje de diversos grupos desasistido. (Unesco, 1990, p. 2)

Tal y como se observa, los Estados, bajo el liderazgo de sus gobernantes, iniciaron el tránsito por las reformas educativas, enmarcadas en una política que más adelante se llamaría inclusión, pero aún era necesario continuar el debate, ya que hasta ese momento la reflexión estaba dada desde los principios de los Derechos Humanos. Es así como en 1993 la onu publica las Reglas estándar sobre la igualdad de oportunidades para personas con discapacidad, un documento esencial para comprender y enfrentar el problema de la discapacidad, centrado en las condiciones que se requieren para una efectiva igualdad y participación.

Un segundo planteamiento de la inclusión, liderado en la Conferencia de Salamanca en 1994 de la Unesco, se basa en las necesidades educativas especiales, cuyo evento convocó a más de 300 participantes de 92 gobiernos. Allí, el concepto de necesidades educativas especiales surge en los discursos y, por ende, en las reformas educativas en Latinoamérica, fomentando una cultura global a favor de la inclusión; de este modo, se plantea que todas las formas de segregación son ética y socialmente inaceptables. Otro elemento rector al 
respecto se estableció en el Foro Mundial sobre Educación en Dakar, Senegal (Organización de las Naciones Unidas para la Educación, la Ciencia y la Cultura [Unesco], 2000): Educación para Todos debe tener en cuenta las necesidades de los pobres y los que están en mayor desventaja, incluyendo a los niños que trabajan, los habitantes de las regiones remotas, los nómades, las minorías étnicas y lingüísticas, niños, jóvenes y adultos afectados por los conflictos, HIV/sIDA, hambre y deficiente salud, y aquellos con necesidades especiales de aprendizaje. Para atraer y retener niños de los grupos marginados y excluidos, los sistemas educativos deberían responder con flexibilidad.

Es evidente entonces que el planteamiento de educación no logra abarcar todos los elementos que en la práctica implica la atención a la diversidad, y es el término gestión, traído del contexto empresarial, el que le da una connotación mayor a la institución educativa. La Unesco (2016) expresa lo siguiente:

La gestión educativa puede entenderse como las acciones desarrolladas por los gestores que pilotean amplios espacios organizacionales. Es un saber de síntesis capaz de ligar conocimiento y acción, ética y eficacia, política y administración en procesos que tienden al mejoramiento continuo de las prácticas educativas. (p. 16)

En realidad, la gestión educativa se configura desde tres elementos fundamentales para la organización: reflexión, decisión y liderazgo. No obstante, diez años después de la declaración de Educación para Todos, esta ameritaba una evaluación en términos de cobertura en la educación básica, la disminución del analfabetismo y la llegada de todos los niños, niñas y jóvenes, sin distinción de raza, etnia, idioma, condición social, económica o de salud, a la Escuela. Así, la gestión educativa es la llamada a ser evaluada: "Los centros educativos hacen una adaptación local muy fuerte de la política educativa y la forma en que los centros funcionan como organizaciones, son factores claves en la adaptación de las políticas" (Aristimuño, 2012, citado por Aldana, Castro, Gómez, \& Ramírez, 2013, p. 230). Sin embargo, era necesario continuar con la implementación de políticas y reformas a las ya existentes. En este sentido, Grindle (2000) expresa lo siguiente: "Muchos países han avanzado hacia el diseño e introducción de reformas mayores en la política y prácticas educativas. Sin embargo, a menudo las experiencias de reforma han sido recibidas con desconfianza y protestas, en lugar de apoyo y consenso" (p. 1).

Sobre la base de las consideraciones anteriores, los lineamientos internacionales no satisfacían las necesidades ni expectativas de los ciudadanos, que recibían las reformas educativas como impuestas por criterios económicos; en 2008, la Conferencia Internacional de Educación número 48, llevada a cabo en Ginebra, Suiza, trazó estrategias para responder a las características diversas de los estudiantes, fijando la atención en poblaciones vulnerables del sector educativo con la intención clara de evitar la discriminación. De este modo, la inclusión se convierte en una propuesta de constante construcción que, ubicada en un marco de derechos a la educación, posibilita identificar los direccionamientos 
de participación de los sujetos educativos y comprensiones de dichas políticas por parte de los actores educativos.

Otra perspectiva de la diversidad se aleja del sistema educativo y se enmarca desde las relaciones sociales; en ese sentido Muñoz (2002) dice lo siguiente:

Así las cosas, la diversidad es consecuencia de la racionalidad humana de responder adaptativa y creativamente a su entorno y necesidades, pero no es la meta de las relaciones humanas ni de la educación; constituye funciones de intercambio y del balance tanto a nivel del individuo como de las interacciones de todo el conjunto social. (p. 12).

De todo esto se desprende el pensamiento divergente frente a la política pública de inclusión. Al respecto, Tedesco (2008) destaca la relevancia que tiene el concepto de sociedad justa, en el que el ideal de justicia social asume hoy un significado renovado, frente a la tendencia a la exclusión, la desigualdad y la fragmentación que muestra el capitalismo ligado a la pura lógica del mercado. Sarto (2009) fundamenta sus planteamientos desde el criterio de la inversión considerada blanda, o sea desde lo social, y propone la organización como la encargada de asumir procesos de cambio e innovación, cuyos resultados serán positivos confluyen factores personales relacionados con la motivación, la actitud, los conocimientos y las condiciones mínimas de incentivación.

En consecuencia, estos cambios estructurales del sistema educativo han generado en la inclusión educativa el paso de ser una actividad exclusiva de un sistema central a una actividad que esta permeada por un conjunto de sistemas que se configuran como políticas públicas, con la tendencia a definirse en relación con entidades administrativas, en el marco de eslóganes de gobiernos que se enmarcan en cobertura y calidad. No es de calidad una educación que expulsa a un importante porcentaje de sus ingresantes. Históricamente las políticas públicas de inclusión son construidas bajo un enfoque de derechos y responden al desafío de la igualdad distributiva de las oportunidades en el sector educativo; sin embargo, la expulsión del sistema educativo de un importante número de estudiantes genera conflictos entre la realidad del estudiante, la política pública y los docentes. Por su parte, Libreros (2002) expresa lo siguiente:

Las transformaciones, reformas y cambios en ese sector han sido afectadas por los lineamientos formulados por agentes internacionales y entidades como el Fondo Monetario Internacional y el Banco Mundial, especialmente en la década de los 80, los cuales han demandado la descentralización administrativa en la educación. (p. )

Con referencia a lo anterior, en el contexto latinoamericano se hacen aportes importantes como la declaración Hacia una estrategia para la inclusión educativa y social de la infancia y la adolescencia con capacidades diferentes, realizada en Perú en 2004, y el proyecto regional Población afrodescendiente de América Latina, que se empezó a ejecutar en el 2009 como iniciativa del Programa de las Naciones 
Unidas para el Desarrollo (PNUD). Ahora bien, los países de América Latina presentan características comunes frente al nivel de desarrollo y a las necesidades sentidas en el campo educativo, aunque existen también diferencias culturales y gubernamentales. El hecho de ser persona -independientemente de su raza, nivel socioeconómico, características personales, etc. - confiere los mismos derechos humanos y legales que al resto de los ciudadanos, que van incluso más allá del ámbito educativo y que se manifiestan también con fuerza en otros sectores como el laboral, el de la salud, el de participación social; es decir, la preocupación en torno a la inclusión apunta claramente a todas las esferas que, de algún modo, tienen que ver con la calidad de la vida de las personas. Es aquí donde comienza a emerger el conflicto, pues la inclusión necesariamente está ligada a la exclusión. Castell (citado por Karsz, 2004) afirma que históricamente hay varias formas de exclusión, una de ellas consistente en dotar a ciertas poblaciones de un estatuto especial que les permite coexistir en la comunidad (no se les encierra ni se les coloca necesariamente en guetos), que les priva de ciertos derechos y de la participación en determinadas actividades sociales.

Es muy valioso comprender las representaciones que se construyen sobre la inclusión, puesto que esto genera una disposición de trabajo hacia el otro. Emergen encuentros y desencuentros que, desde la reflexión, desencadenan el quebrantamiento de la política pública de inclusión, un quebrantamiento que se enmarca, en primera instancia, en el desconocimiento de la norma, en el que se justifica la exclusión desde el debe ser la educación para todos; en segunda instancia, en la diferencia en las condiciones de los maestros en el sistema educativo, y en tercera instancia, en el afán del reconocimiento por la política de calidad, convirtiéndose la inclusión en una estadística de cobertura.

Más allá del concepto de inclusión, Echeita (2008) entiende la inclusión educativa con igual fuerza como la preocupación por un aprendizaje y un rendimiento escolar de calidad y exigente con las capacidades de cada estudiante. Allí, se evidencia nuevamente el llamado constante a avanzar, pasando de la política impresa en el papel al cumplimiento de lo misional en el sistema educativo, materializada desde la gestión educativa. Aunque hay una crítica manifiesta en Tenti (2008), las políticas compensatorias realmente existentes merecen un examen crítico, en la medida en que no logran romper con los círculos viciosos de la pobreza social y escolar. Emerge entonces la controversia, el abandono y la soledad que vive la gestión educativa por parte del Estado, que impide la implementación y mejoramiento continuo, reduciendo el actuar al interior de la institución educativa a una mínima expresión. Se manifiesta en el índice, en la estadística, que termina segregando y categorizando a los estudiantes según su caracterización biopsicosocial.

Igualmente, la trayectoria de historicidad que tiene el concepto de inclusión implica asumir ciertas acciones, como desregularización, flexibilización, descentralización y privatización, en las que lo privado coloniza lo público, penetrando en el nivel cultural para existir. Esto conlleva a una gestación categorial que se manifiesta en la crisis de la propia modernidad, exigiendo trascender 
las posturas de los modelos de la prescindencia y el de rehabilitación hacia la flexibilidad de los postulados que enuncia el modelo contemporáneo social.

\section{Representaciones de la inclusión: utopía de la gestión educativa en Colombia}

El interés para indagar y comprender las representaciones de la política pública de inclusión surge cuando se remite a la literatura especializada y se encuentra que las representaciones se construyen como una forma particular del conocimiento que permiten las relaciones entre las personas y el marco de lectura de la realidad. Como lo plantea Farr (1986, citado por Mora, 2002), dichas representaciones aparecen cuando los individuos debaten temas de interés mutuo o cuando existe el eco de los acontecimientos seleccionados como significativos o dignos de interés. Plantear la utopía refleja la realidad de la implementación de la política pública de inclusión, entendida la utopía como la "representación imaginativa de una sociedad futura de características favorecedoras del bien humano" (Real Academia de la Lengua, 2016); dicha definición tiene una estrecha relación con la que el Ministerio de Educación de Colombia (MEN) da al término calidad educativa, en la que se plantea que todos los estudiantes, independientemente de su procedencia, situación social, económica y cultural, cuenten con oportunidades para adquirir conocimientos, desarrollar las competencias y valores necesarios para vivir, convivir, ser productivos y seguir aprendiendo a lo largo de la vida (MEN, 2008). Es decir, se propone un ideal de sistema educativo.

Resulta oportuno hacer un alto y revisar el concepto de educación. Por ejemplo, Zemelman (2008) considera que, para el análisis de la educación en América Latina, es imprescindible deliberar sobre el contexto, el discurso teórico-político, la globalización y la subjetividad, con el fin de enfrentar desafíos técnicos y políticos, más allá del currículo, como la redefinición del concepto de educación; sin embargo, otros autores plantean el concepto de educación desde la represión del Estado. Como lo expresa Althusser (1970, citado por Ruiz, 2014), la unidad del aparato represivo de Estado queda asegurado por su organización centralizada que ejecuta la política de las clases en el poder. Rousseau planteó la educación en términos de obligaciones y derechos; por lo tanto, el Estado tiene la obligación de formular las políticas públicas necesarias para garantizar los derechos de todos los ciudadanos. La Real Academia de la Lengua (2016) define educación como "crianza enseñanza y doctrina que se da a los niños y a los jóvenes por medio de la acción docente", definición excluyente de las configuraciones de la modernidad y la posmodernidad.

Se observa claramente que las conceptualizaciones en torno a la gestión educativa y a la educación misma requieren una comprensión desde las representaciones sociales, que "se constituyen en un corpus organizado de conocimientos, y en actividades psíquicas gracias a las cuales los hombres hacen inteligible la realidad física y social, se integran en una relación cotidiana de intercambios y 
liberan poderes de su imaginación" (Moscovici, 1979, pp. 17-18). El estudio de las representaciones sociales en los actores educativos cobra importancia en la aceptación de algunas políticas y en otras no, formándose el sentido subjetivo en la vida histórico-sociocultural, en contraste con los contextos actuales de esa vida social. El esquema actual de financiamiento de las políticas sociales, y en particular de las políticas educativas, es insuficiente para lograr la garantía plena del derecho a la educación inclusiva y de calidad para todas y todos (Save the children, 2006).

Por otra parte, Colombia no ha sido ajena a las políticas internacionales, que han permeado la configuración de Estado. En 1991, cuando se consolida la Carta Magna y se promulga en su Artículo 1 lo siguiente: "Colombia es un Estado social de derecho organizado en forma de República unitaria, descentralizada, con autonomía [...] democrática, participativa y pluralista, fundada en el respeto de la dignidad humana, en el trabajo y la solidaridad de las personas que la integran y en la prevalencia del interés general" (Constitución Política de Colombia, 1991), al mismo tiempo se está viviendo a nivel mundial la promulgación de los Derechos de la Niñez y la aprobación de la declaración mundial sobre la educación para todos, que tuvo su origen en 1990 en Jomtien, Tailandia. Estos acontecimientos afectaron directamente los fines fundamentales de la Constitución, en cuyo Artículo 5 promulga lo siguiente: "El Estado reconoce, sin discriminación alguna, la primacía de los derechos inalienables de la persona y ampara a la familia como institución básica de la sociedad" (Constitución Política de Colombia, 1991).

No obstante, fue necesario que durante el mismo año el Gobierno nacional legislará la Ley 12, que permite la transformación social de la niñez y la implementación de mecanismos legales, para su protección integral. Es decir, Colombia iniciaba el camino de transformación, ante la sociedad tradicional, que quebrantaba el orden establecido, un orden monótono que implicaba el control; es así como en 1994 se presenta ante los ciudadanos la Ley 115, considerada la Ley General de Educación Colombiana, como la encargada de señalar las normas generales para regular el servicio educativo, entendida la educación como un proceso de formación permanente, personal, cultural y social. Dicha Ley es señalada desde la falta de contexto y en argumentos de los movimientos sindicalistas no refleja la realidad de país, ni satisface las necesidades de los ciudadanos, como lo expresa Marín (2005):

Al examinar la literatura jurídico-político-educativa de algunos países iberoamericanos y los desarrollos de la ley 115 de 1994, y después de someterla a un estudio comparado con las normas de educación de países específicos como España, es sorprendente y desalentador hallar tantas similitudes y al entrar con detenimiento poder afirmar que, ley 115 de 1994 es una copia-compendio sistémica de leyes españolas, dadas desde 1985 hasta 1992. (p. 102)

Entonces, ¿cómo implementar una política educativa, distante de la realidad y del contexto? Es posible que no se dé una respuesta explícita, aunque el comienzo 
del sistema educativo - considerado el sustento para el orden jerárquico, cimentado en el desconocimiento de los acuerdos propios y de las representaciones sociales como características de época, donde prevalece la abundante información - genera momentos de crisis supeditados a condiciones referidas a la dispersión de la información, a la comprensión de las normas desde la individualidad; emergen nuevas configuraciones de sentido.

No obstante, en 1998 Colombia presenta la primera Política Pública Educativa, denominada Revolución Educativa, pero es hasta el 2002 que el MEN muestra de una forma muy incipiente la inclusión, en el discurso dado por la entonces ministra de educación ante la Asociación Nacional de Empresarios de Colombia (ANDI, 2002):

Durante los próximos cuatro años la educación tendrá un importantísimo avance en cobertura. Este avance se tendrá que dar en simultánea con procesos de mejoramiento de la calidad. La educación es un asunto de justicia y de equidad. Si esto es lo que queremos, tenemos que incluir en el sistema educativo a todos los niños y jóvenes de Colombia, haciendo énfasis en los más vulnerables. El propósito es ofrecer acceso a una educación mejor a más estudiantes y en más lugares de Colombia.

Entonces ya se evidenciaba la relación entre la inclusión y las estadísticas de cobertura, y aflora el modelo de rehabilitación, en la materialización de la integración, una falacia de inclusión. Esto significa un descuido: que los niños, niñas y jóvenes tienen la posibilidad de repensar y proponer nuevas posibilidades de ver el mundo; "la inclusión es una nueva retórica que sostiene que la escuela se debe fundamentar en nuevos conceptos, emplear nuevas prácticas y erigir nuevos medios e instituciones" (Soto, 2008, p. 20 ). De este modo, se plantea la reestructuración de la escuela y el cambio en el paradigma de la práctica educativa.

\section{La discusión}

La definición del concepto de gestión educativa permite potenciar las instituciones que se dedican a la formación, a partir de un conjunto de acciones intencionadas y que permean la totalidad de la comunidad educativa, con el propósito de favorecer los procesos de las instituciones de manera contextualizada. Es así como el MEN (2008) publica en su página institucional lo siguiente:

La gestión en los establecimientos educativos, es un proceso sistemático que está orientado al fortalecimiento de las instituciones educativas y a sus proyectos, con el fin de enriquecer los procesos pedagógicos, directivos, comunitarios y administrativos; conservando la autonomía institucional, para así responder de una manera más acorde, a las necesidades educativas locales, regionales y mundiales. 
Así, el proceso de inclusión representa un enfoque lógico para establecer la dirección futura de las instituciones educativas; sin embargo, hay demasiados intereses en juego para que la gestión educativa tome sus decisiones de forma intuitiva, sin usar los conceptos y técnicas de la gerencia estratégica. De esta manera, la gestión educativa está relacionada con la sensibilidad, el saber técnico y el saber relacional, en cuyo sentido Tello (2008) plantea lo siguiente:

Gestionar sin otros es imposible, pero encontrarlos, verlos, no es poco, ni es tan sencillo. Las situaciones de alta dificultad y de profundo sufrimiento promueven salidas que reniegan, que sacan de circulación, que imaginan acciones mágicas para transformar al otro según nuestro deseo. Gestionar con otros implica un miramiento, en tanto mirada que lo reconoce en su trayectoria, en su diferencia. (p. 9)

En este orden de ideas, es importante resaltar la existencia de factores que favorecen, o no, la implementación de las políticas públicas inclusivas, que se encuentran categorizados desde una perspectiva de oportunidades de mejoramiento continuo.

En Colombia los factores limitantes se presentan en la contradicción y ambigüedad que la gestión educativa vive, frente a la urgencia de atender al estudiante en el marco de los derechos, la igualdad y la equidad, en la implementación de políticas que se anulan entre sí: el Decreto 366 de 2009 - que reglamenta la organización del servicio de apoyo pedagógico para la atención de los estudiantes con discapacidad y con capacidades o con talentos excepcionales en el marco de la educación inclusiva-, versus la Norma Técnica 4585 de 1999 - que determina el número de estudiantes por aula según el área de esta - ; o el Decreto 1421 del 2017 - por el cual se reglamenta en el marco de la educación inclusiva la atención educativa a la población con discapacidad, e introduce los conceptos de barreras visibles o invisibles - , versus instituciones con plantas físicas hasta con 30 años de antigüedad, que en sus orígenes no se pensaron para el acceso de todos y todas.

\section{Conclusiones}

Comprender el recorrido que hace la política desde su origen, y su tránsito por la filosofía y las ciencias, permite reflexionar acerca del papel del hombre en la sociedad; en la revisión de época se encuentra un hombre sujeto de un Estado que no logra la trascendencia de los sistemas que permitan verdaderas trasformaciones sociales. Así, el anclaje del sistema educativo hace evidente la involución en la comprensión de la discapacidad, asociada al sujeto defectuoso que no tiene "arreglo", con una participación posterior del sistema de salud, que igualmente la presenta como una enfermedad que debe ser resguardada, escondida para la rehabilitación. Aunque la posmodernidad trajo lo social a la atención a la discapacidad, aún el miedo a lo desconocido y las tensiones frente 
a la diferencia invaden de forma negativa la atención desde la diversidad.La política pública de inclusión se enfrenta al paradigma que ha impactado todos los ámbitos desde el micro, meso y exosistema, hasta el macrosistema, que debe transitar con los principios de democracia, corresponsabilidad, libertad, autonomía, equidad y diversidad, para apostarle a una igualdad de derechos, en la que las necesidades de cada persona tiene igual importancia; sin embargo, en su formulación resulta excluyente, ya que hace especial énfasis en la discapacidad, prevaleciendo la atención de unos pocos sobre el beneficio general, de modo que se evidencia la exclusión como excusa para la inclusión.

En Colombia el tránsito de la inclusión se gesta desde hace 27 años, aunque el desafío se ha convertido en una utopía que genera la desesperanza frente a un sistema educativo legislado en el marco de los acontecimientos latinoamericanos, pero que viciado por el sistema económico desvía no solo los recursos sino también los lineamientos educativos, dejándolos a merced de los requerimientos de organismos como la Organización para la Cooperación y el Desarrollo Económicos (OCDE). Este tipo de organizaciones determina el crecimiento económico según los resultados en las pruebas estandarizadas, considerado un indicador de calidad que homogeniza un sistema educativo que direcciona la permanencia de los estudiantes en el aula amparado en teorías psicológicas, bajo la cual según la edad todos los niños, niñas y jóvenes deben cumplir con los mismos parámetros. Estos son algunos de los hechos a los que se enfrenta la inclusión, quedando reducida al cumplimiento del indicador de acceso y permanencia, al número de estudiantes diagnosticados y a la presión diaria del maestro para desarrollar un currículo diseñado para todos, en igualdad de condiciones, en el aula de clase diversa en raza, cultura, creencias, desarrollo biosicosicial, motivaciones, etc., en el desconocimiento del maestro como un sujeto diverso que también necesita de la inclusión.

\section{Consideraciones para futuras investigaciones}

De la revisión del estado del arte aquí presentado, se pueden considerar varias propuestas de investigación: una es indagar sobre la comprensión que tienen los otros, los que no están en la escala de la discapacidad, de la excepcionalidad, de la vulnerabilidad, sobre la inclusión; otra, sobre el currículo oculto en las relaciones escolares en el marco de la inclusión y, por último, las limitaciones y alcances de los niños y niñas en condición de vulnerabilidad en la trazabilidad de la vida escolar.

\section{Referencias}

Ainscow, M. (2005). Developing Inclusive Education Systems: What Are the Levers for Change? Journal of Educational Change, 6(2), 109-124. Dor: https:// doi.org/10.1007/s10833-005-1298-4 
Aguado, A. (1995). Historia de las deficiencias. Madrid: Escuela libre editorial. Recuperado de https://sid.usal.es/idocs/F8/8.1-5051/librohistoriadelasdeficiencias.pdf

Aguado, T. (2004). Investigación en educación intercultural. Educatio, 22, 39-57.

Alarcón, V. (2007). Política y derecho. México: Editorial Anthropos. Recuperado de https://losapuntesdefilosofia.files.wordpress.com/2018/04/tratado ciencia politicagee-vao1.pdf

Aldana, C., Castro, L., Gómez, A., \& Ramírez, B. (2013). Comprensiones y representaciones que se derivan de la incorporación de la política de inclusión desde la gestión directiva. Plumilla Edcuativa, 12(2), 227-249. Dor: https:// doi.org/10.30554/plumillaedu.12.381.2013

Azcárate, P. (1873). Obras de Aristóteles. Madrid: Sin editorial.

Constitución Política de Colombia. (1991). Gaceta Constitucional N. $\stackrel{\text { 116 }}{11} 20$ de julio de 1991 Presidencia de la República: Santa Fe de Bogotá.

Real Academia de la Lengua Española. (2016). Utopía. Recuperado en https:// dle.rae.es/?w=utop $\%$ C3\%ADa

Echeita, G. (2008). Inclusión y exclusión educativa. "Voz y quebranto". REICE, Revista Iberoamericana sobre Calidad, Eficacia y Cambio en Educación, 6(2), 9-18. Recuperado de https://www.redalyc.org/articulo.oa?id=55160202

Echeita, G., Simón, C., Verdugo, M. A., Sandoval, M., López, M., Calvo, I., \& Gonzáñez-Gil, F. (2009). Paradojas y dilemas en el proceso de inclusión educativa en España. Revista de Educación, 349, 153-178. Recuperado de http:// www.educacionyfp.gob.es/dam/jcr:15c3ba6d-3320-410f-aafd-1b688f3200f7/ re34908-pdf.pdf

Emmerich, G., \& Alarcón, V. (2007). Tratado de ciencia política. México: Anthropos. Recuperado de http://www.izt.uam.mx/mydes/wp-content/ uploads/2016/03/Tratado Ciencia PoliticaGEE-VAO1.pdf

Esposito, R. (2004). Bíos, biopolítica y filosofía. Buenos Aires: Amorrortu.

González, M. (2008). Diversidad e inclusión educativa: Algunas reflexiones sobre el liderazgo en el centro escolar. REICE, Revista Iberoamericana sobre Calidad, Eficacia y Cambio en Educación, 6(2), 82-99. Recuperado de http:// www.redalyc.org/articulo.oa? $\mathrm{id}=55160208$

Grindle, M. (2000). La paradoja de la reforma educacional: pronosticar el fracaso y encontrar el progreso. Chile. PREAL. Recuperado de http://www.crenamina.edu. $\underline{\mathrm{mx} / \mathrm{Rieb} / 1 \mathrm{MODULO} \text { RIEB } 10 \text { y } 60 \text { GRADOS DE EDUC PRIMARIA/ }}$ La paradoja de la reforma educacional1 PREAL.pdf 
Infante, M. (2010). Desafíos a la formación docente: Inclusión educativa. Estudios Pedagógicos, 36(1), 287-297. Dor: http://dx.doi.org/10.4067/ $\underline{\text { S0718-07052010000100016 }}$

Karsz, S. (2004). La exclusión, bordeando sus fronteras, definiciones y matices. Barcelona: Gedisa.

Asociación Nacional de Empresarios de Colombia (ANDI). (2002). La Revolución Educativa. Cartagena: ANDI.

Lazzarato, M. (2006). Política del acontecimiento. Buenos Aires: Tinta limón. Recuperado de https://www.academia.edu/35846075/44977322-PoliticasDel-Acontecimiento-Maurizio-Lazzarato-1 1 .pdf

Libreros, D. (2002). Tensiones de las políticas educativas en Colombia, Balance y perspectivas, Unidad de prospectivas y políticas educativas. Bogotá. Universidad Pedagógica Nacional.

Marín, L. (2005). Critica y educación: Ensayos sobre las reformas educativas en Colombia. Armenia.

Ministerio de Educación Nacional (MEN). (2008). Guía para el mejoramiento institucional. De la autoevaluación al plan del mejoramiento. Serie de guías N. 34 . Recuperado de http://www.mineducacion.gov.co/1621/articles-177745_archivo pdf.pdf

Moliner, O. (2008). Condiciones, procesos y circunstancias que permiten avanzar hacia la inclusión educativa: retomando las aportaciones de la experiencia Canadiense. REICE, Revista Iberoamericana sobre Calidad, Eficacia y Cambio en Educación, 6(2), 27-44. Recuperado de https://revistas.uam.es/index.php/ reice/article/view/5439/5877

Mora, M. (2002). La teoría de las representaciones sociales de Serge Moscovici. México. Athenea Digital, Revista de Pensamiento e Investigación Social, 2, 1-25. Dor: https://doi.org/10.5565/rev/athenead/v1n2.55

Moscovici, S. (1979). El Psicoanálisis, su imagen y su público. Buenos Aires: Huemul.

Muñoz, H. (2002). La diversidad en las reformas educativas interculturales. Revista Electrónica de Investigación Educativa, 4(2), 1-22. Recuperado de https://www.redalyc.org/articulo.oa?id=155/15504201

Navarro, J. (2006). Dos clases de políticas educativas. La política de las políticas públicas. Buenos Aires: preAL.

Organización de las Naciones Unidas (ONU). (1989). Convención sobre los derechos del niño. Nueva York: Asamblea General de las Naciones Unidas. 
Organización de las Naciones Unidas (ONU). (1996). Reglas estándar sobre la igualdad de oportunidades para personas con discapacidad. Madrid: Lumen.

Organización de las Naciones Unidas para la Educación, la Ciencia y la Cultura (Unesco). (1990). Declaración Mundial sobre Educación para Todos. Jomtien: Unesco.

Organización de las Naciones Unidas para la Educación, la Ciencia y la Cultura (Unesco). (1994). Declaración de Salamanca y marco de acción de acción sobre necesidades educativas especiales. París: Unesco.

Organización de las Naciones Unidas para la Educación, la Ciencia y la Cultura (Unesco). (2000). Foro mundial sobre educación. Dakar: Unesco.

Organización de las Naciones Unidas para la Educación, la Ciencia y la Cultura (Unesco). (2016). Gestión educativa. Buenos Aires: IIPE.

Palacios, A. (2008). El modelo social de discapacidad: orígenes, caracterización y planeación en la Convención Internacional sobre los Derechos de las Personas con Discapacidad. Madrid: Cermi.

Rendón, C. (2012). Reconocimiento como inclusión: El legado democrático de la filosofía política de Hegel. Universitas Philosophica, 59(29), 51-64.

Ruiz, R. (2014). Miradas, reflexiones y procesos de orientación de la políticas de educación inclusiva. Armenia: Kinesis.

Sarto, M. (2009). Aspectos claves de la educación inclusiva. Salamanca: inico. Recuperado de http://inico.usal.es/publicaciones/pdf/Educacion-inclusiva. pdf\#page $=21$

Save the Children. (2006). Documento Financiamiento y Presupuestos Públicos en Educación. Reino Unido.

Skliar, C. (2002). Alteridades y pedagogías o... ¿si el otro no estuviera ahí? Educação E Sociedade, 23(79), 85-123. Dor: http://dx.doi.org/10.1590/ $\underline{\mathrm{S} 0101-73302002000300007}$

Soto, N. (2008). Representaciones Sociales y Discapacidad. Buenos Aires: Hologramática.

Tedesco, J. (2008). Educación y sociedad justa. En E. Boscho (Ed.), Educación y vida urbana: 20 años de ciudades educativas (pp. 229-238). Barcelona: Santillana.

Tello, C. (2008). Gestionar la escuela en Latinoamérica. Gestión educativa, realidad política. Revista Iberoaméricana de Educación, 45(6), 1-10. Dor: https:// doi.org/10.35362/rie4562024 
Tenti, E. (2008). Dimensiones de la exclusión educativa y políticas de inclusión. Revista Colombiana de Educación, 54, 60-73. Dor: https://doi.org/10.17227/01 203916.54rce60.73

Zemelman, H. (2008). Pensar teórico y pensar epistémico: los retos de las ciencias sociales latinoamericanas. Ciudad de México: Instituto Pensamiento y Cultura en América Latina. 